\title{
APPLICATION OF A LOGARITHMIC MODEL ON A STRESS - DEFORMATION INTERDEPENDENCE OF THE RECYCLED TIRES
}

\author{
Anđelko CRNOJA, Željko KOS, Oleg POPOV
}

\begin{abstract}
During the last two decades, technological development has led to an extreme increase in transport and connected industries. This has significantly increased the production of automobile tires, which have their life span after which they go to waste. It is therefore necessary to extricate new products from recycled raw materials. For a product to be created, it is necessary, especially in civil engineering, to examine and determine all the properties of this material (pressure, traction, stress resistance, etc.). The results obtained by the research in this paper are mathematically processed by applying a logarithmic model. The aim of this process is to predict stress deformation in terms of tensile force. The model obtained is significant with accuracy of $87.21 \%$ and has a very high accuracy of the deformation estimation in relation to the applied stress. Independent variables were granulometric composition, binder (glue) and specific mass.
\end{abstract}

Keywords: deformation; logarithmic model; recycled rubber; stress

\section{INTRODUCTION}

For a long time, it was deliberated how to recycle the vehicle tire to create new products in many areas of human activity and because of the rubber properties, the same applies for civil engineering and construction industry. After the establishment of technological recycling processes, we started investigating the effects on human health. One of the main reasons for the recycling process is the procedure for disposal's harmful impact on the environment, nature and human health as it is complicated and the waste is environmentally hazardous [1]. Certain authors tell us about the performance of certain rubber components on human health and its association with the occurrence of certain diseases [2-6]. The beginnings of recycling were in the United States in the 1960s and in Europe, recycling of tires began in the 1980s [7]. The first products that were produced from recycled vehicle tires were developed by the construction industry, and were mainly rubber floors for sports grounds. Different methods are being developed today and different technological processes are sought - those that can produce products widespread in different sectors of the economy, especially in civil engineering as an engine of the overall economy. It is very important to know the properties of each material so that its behavior can be determined in different situations. When performing the test, the measurement procedures should be carried out according to the applicable norms in order to be comparable and useful. Such results should be dealt with from various aspects to obtain relevant and correct information that is especially important when new products in construction industry are developed and that tells us what material it is and what kind of properties it has. The aim of this study is to show results and to direct further research towards proving that the products from recycled automotive tires have potential and that such waste from the environment can and should become a source of raw materials for wider application. It should be noted that the geographical location of the recycling facility is in the north-western Croatia [8]. Used tires are mostly collected from a wider area. This is important because every production facility has different technology, access, quality, granulometric composition, quantity and type of binders (glues) used, and other parameters that are specific to the individual manufacturer, reflecting the quality of the raw material to produce samples/products. The geographic position of producers and collectors of spent car tires in the world is an important fact because the various climatic impacts, traffic management arrangements, etc., are determining quality of tire and tire composition for a wider area of tire use.

\section{MATERIAL AND METHODS}

\subsection{Basic Features of the Application of a Mathematical Logarithmic Model}

The tests were carried out on the axial device for the application of tensile force in terms of the test of resistance to stretching. Test details can be found in Fig. 1.

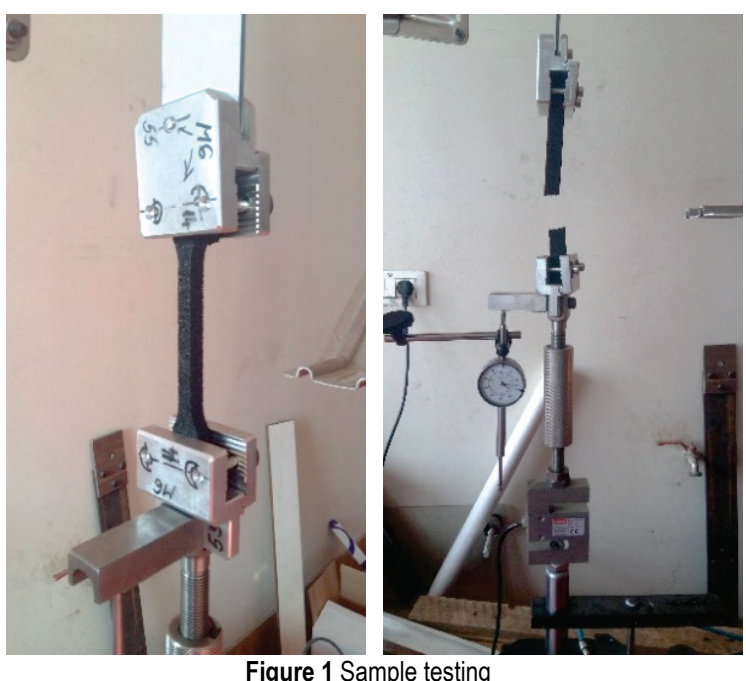

Figure 1 Sample testing 
The results were processed using a logarithmic model. Such a model is applied when we have multiple independent variables each of which is subject to logarithm. Then, control of the model is done in terms of its correctness, significance, etc. Such actions are needed to prove its realistic application. The proposed model predicts with certain accuracy the deformation of the real sample in relation to the assumed stress provided that the known values for the specific mass and binder amount are known. The minimum accuracy must be $80 \%$ to make the model applicable and acceptable. In such conditions we get a mathematical expression so that the mentioned sizes can be calculated.

\subsection{Main Characteristics of the Test Samples}

The samples were manufactured according to the valid norm [9] and as such were tested on the axial device. Load appliance is manual, and monitored and read through measuring devices. The following figure shows the test specimen according to HRN EN ISO 527-4: 2008 (for testing of the tensile strength of polymeric materials) [9]. The detailed dimensions of the sample are shown in Fig. 2.

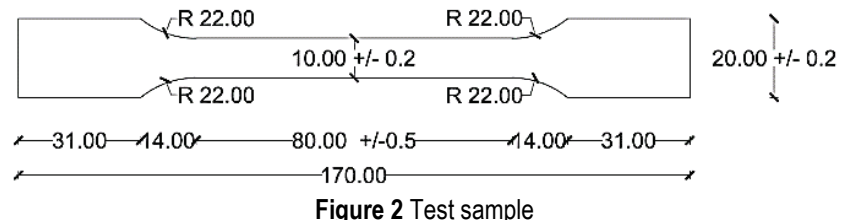

Samples were prepared according to the following different characteristics:

1) Specific mass

2) Granulometric composition

3) The amount of binders

4) Geometric Characteristics (Sample Thickness).

The specific mass ranges from $\min 585 \mathrm{~kg} / \mathrm{m}^{3}$ to $\max$ $1100 \mathrm{~kg} / \mathrm{m}^{3}$.

The granulometric composition is divided into 3 groups, namely:

1) A granulate of $0.5-2.0 \mathrm{~mm}$

2) A granule of $2.0-3.5 \mathrm{~mm}$

3) Granulate mix $(0.5-2 \cdot 0-35 \%+2.0-3 \cdot 5-65 \%)$.

Plan of experiment is listed in Tab. 1.

Table 1 Plan of the experiment

\begin{tabular}{|c|c|c|}
\hline Sample thickness & Granulometric composition & $\begin{array}{c}\text { Number of } \\
\text { experiments }\end{array}$ \\
\hline $10 \mathrm{~mm}$ & $0.5-2$ & 3 \\
\hline $10 \mathrm{~mm}$ & $2-3.5$ & 3 \\
\hline $10 \mathrm{~mm}$ & $0.5-2(35 \%)+2-3.5(65 \%)$ & 3 \\
\hline $15 \mathrm{~mm}$ & $0.5-2$ & 3 \\
\hline $15 \mathrm{~mm}$ & $2-3.5$ & 3 \\
\hline $15 \mathrm{~mm}$ & $0.5-2(35 \%)+2-3.5(65 \%)$ & 3 \\
\hline $20 \mathrm{~mm}$ & $0.5-2$ & 3 \\
\hline $20 \mathrm{~mm}$ & $2-3.5$ & 3 \\
\hline $20 \mathrm{~mm}$ & $0.5-2(35 \%)+2-3.5(65 \%)$ & 3 \\
\hline Total & & 27 \\
\hline
\end{tabular}

The amount of binder (polyurethane adhesive) ranges from 29.6 to $67 \mathrm{~kg} / \mathrm{m}^{3}$ of the sample. A single manufacturer may use a different type of binder within the material structure. The tested samples are based on polyurethanebased glue, while other binders such as epoxy can be used, etc., which is especially important in civil engineering, because of the economical acceptance, e.g. production of construction panels for improvement of soundproofing properties on light metal structures and construction panels for making roadside sound barriers.

\subsection{Results of Samples Testing}

Twenty-seven samples were tested with different properties. The changing variables are the granulometric composition, the specific weight, and the amount of the binder. In Fig. 3 we can see a graphic representation of the stress ratio and the associated deformation of a particular sample. In the same figure it can be noticed that there are significant differences in values and that the influence of individual variables in the sample on the results of the test is visible.

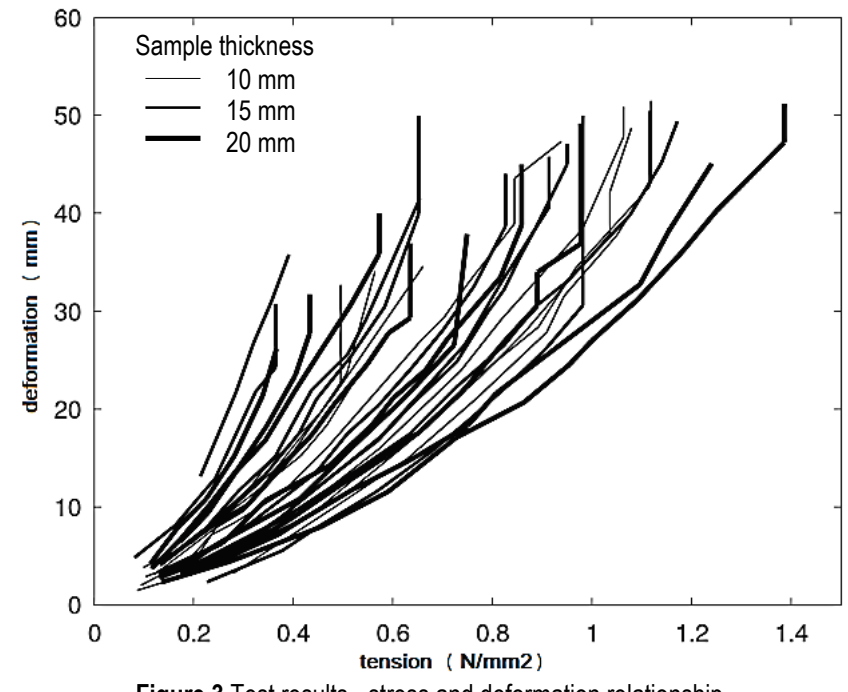

Figure 3 Test results - stress and deformation relationship

\section{APPLICATION OF THE MATHEMATICAL MODEL}

Based on the results presented, we created a database and used the Statistical Package (SPSS) program with the application of a multiple logarithmic model.

In the model shown in Tab. 2, we see that all variables are logarithmized. It should be emphasized that the respective variables are independent of each other, which is one of the conditions for applying the chosen model. The variables that are considered are the following:

1) $\log (\delta)$ - logarithm variable "stress"

2) $\log (\rho)$ - logarithm variable "specific mass"

3) $\log (p u)$ - logarithm variable "polyurethane glue binder".

The model interprets the accuracy of $87.21 \%\left(R^{2}=\right.$ $0.87212527)$ in relation to the given results. This means that 
with an accuracy of $87.21 \%$ we can predict the deformation results in relation to the predicted stress if we apply this model. It should be noted that other independent variables, such as specific mass and amount of binder, must remain invariable, otherwise the model is not valid and cannot be applied.

Table 2 The logarithm results of the test result database

\begin{tabular}{|c|c|c|c|c|c|c|}
\hline \multicolumn{2}{|c|}{ Regression Summary for Dependent Variable: $\log$ deformation (Database) $R=.93387647, R^{2}=.87212527$ Adjusted $R^{2}=.87059077 F(3.250)=568.35 p$} \\
\hline & $b^{*}$ & Std. Err. - of $b^{*}$ & $b$ & Std. Err. - of $b$ & $t(250)$ & $p$-value \\
\hline Intercept & & & 1.49231 & 0.015047 & 99.1744 & 0 \\
\hline $\log (\delta)$ & 1.015547 & 0.024731 & 1.29961 & 0.031649 & 41.0636 & 0 \\
\hline $\log (\rho)\left(\mathrm{t} / \mathrm{m}^{3}\right)$ & -0.304961 & 0.02444 & -1.28938 & 0.103332 & -12.478 & 0 \\
\hline $\log (p u) \mathrm{g} / \mathrm{m}^{2}$ & -0.083137 & 0.02291 & -0.13434 & 0.03702 & -3.6289 & 0.000345 \\
\hline
\end{tabular}

\subsection{Testing Models of Expectation or Significance}

Testing the significance of the model is carried out to determine the level of significance of the test. The test provides the information with which reliability is performed. If the data is such that the probability value of $p<0.05$ we say that the results are acceptable.

Table 3 The test results of the logarithm results-significance base

\begin{tabular}{|l|c|c|c|c|c|}
\hline \multicolumn{5}{|c|}{ Analysis of Variance; DV: log deformation (Database) } \\
\hline & $\begin{array}{c}\text { Sums of - } \\
\text { Squares }\end{array}$ & $d f$ & $\begin{array}{c}\text { Mean - } \\
\text { Squares }\end{array}$ & $F$ & $p$-value \\
\hline Regress. & 26.65913 & 3 & 8.886378 & 568.3461 & 0 \\
\hline Residual & 3.90888 & 250 & 0.015636 & & \\
\hline Total & 30.56801 & & & & \\
\hline
\end{tabular}

According to Tab. 3, the value of factor $p$ is less than 0.05 , and we conclude that the model is correct and reliable.

\subsection{Model Multicollinearity Test}

Multicollinearity testing is performed to determine the correlation of independent variables, or to show us what is the interdependence of the same.

Table 4 The results of the logarithm test results base-multicollinearity Variables currently in the Equation; DV: log deformation (Crnoja database 25.05.2019.)

\begin{tabular}{|c|c|}
\hline & Tolerance \\
\hline $\log (\delta)$ & 0.836293 \\
\hline $\log (\rho)\left(\mathrm{t} / \mathrm{m}^{3}\right)$ & 0.856332 \\
\hline $\log (p u) \mathrm{g} / \mathrm{m}^{2}$ & 0.97453 \\
\hline
\end{tabular}

For multicollinearity analysis it is important that all factors are greater than 0.20. If we look at the model in Tab. 4 , we see that the condition is fulfilled, and the conclusion is that there is no multicollinearity problem.

\subsection{Testing the Model for the Presence of Heteroscedasticity}

The presence of heteroscedasticity does not lead to the estimates obtained by the least squares method being biased, but causes the ratings to have no minimal variation, i.e. are not effective. Hence, if there is heteroscedasticity, no prediction based on the original model's ratings will be effective. The variation of the forecast, apart from the variation of residuals, includes the variation of parameter estimates. Therefore, it must be ensured that the model has no presence of heteroscedasticity [10].

The condition that there is no heteroscedasticity is that the factor $p>0.05$. In Tab. 5, we see that the condition is fulfilled, and we conclude that the model is correct and reliable.

Table 5 The results of logarithm test results base-heteroscedasticity

\begin{tabular}{|c|c|c|c|c|}
\hline \multicolumn{5}{|c|}{$\begin{array}{c}\text { Spearman Rank Order Correlations (Spreadsheet 14) MD pairwise } \\
\text { deleted Marked correlations are significant at } p<.05000\end{array}$} \\
\hline $\begin{array}{c}\text { Residuals \& } \\
\log (\delta)\end{array}$ & Valid - $N$ & Spearman - $R$ & $t(N-2)$ & $p$-value \\
\hline $\begin{array}{c}\text { Residuals \& } \\
\log (\rho)\end{array}$ & 254 & 0.032002 & 0.508281 & 0.611701 \\
\hline $\begin{array}{c}\text { Residuals \& } \\
\log (p u)\end{array}$ & 254 & 0.024431 & 0.387948 & 0.698382 \\
\hline
\end{tabular}

\section{MATHEMATICAL MODEL RESULTS}

After making the logarithmic mathematical model and performing the tests to verify the correctness of the applied model, we conclude that it can be applied with a very high accuracy to predict deformation with known stress. The condition is that the independent variables of the specific mass and amount of polyurethane adhesive are known and unchangeable. This is ensured by the technological process of production for a given product. Based on the abovementioned requirements, the model defined the mathematical expression that we can use to make such calculations. By studying the results of the multiple logarithmic model, we came to the following mathematical expression:

Logarithmic form of equation:

$\log \varepsilon=1.49+1.2996 \log \delta-1.289 \log \rho-0.134 \log p u$

Basic form of equation:

$\varepsilon=31.07 \delta^{1.30} \rho^{-1.29} p u^{0.134}$

Where: $\varepsilon$-deformation, $\delta$ - stress (MPa), $\rho$ - specific mass $\left(\mathrm{t} / \mathrm{m}^{3}\right), p u-$ glue $\mathrm{g} / \mathrm{m}^{2}(\mathrm{~kg})$.

After defining the mathematical expression to determine the value of the deformation value in relation to the given load, it is necessary to note the significant influence of certain areas in the test zone curve. These are the minimum and maximum values that have a significant impact on the actual model. The actual model represents the test case from which the model base was created. This means that the impact of the accuracy error we have noted initially depends to a great extent on these values. In Tab. 6, we see the above values that have a significant impact on the mathematical model predicting the deformation size. 
Table 6 Overview of the influential minimum and maximum from the model base Standard Residual: $\log \log$ deformation (Database) Outliers

\begin{tabular}{|c|c|c|c|c|c|c|}
\hline $\begin{array}{l}\text { Number of } \\
\text { observation }\end{array}$ & 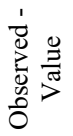 & 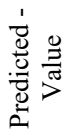 & 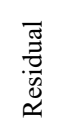 & 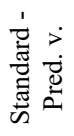 & 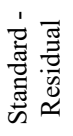 & 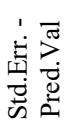 \\
\hline$\left.50 \ldots\right|^{*} \ldots$ & 0.59 & 0.30 & 0.28 & -2.83 & 2.26 & 0.03 \\
\hline $56 \ldots \mid{ }^{*} \ldots$ & 1.51 & 1.09 & 0.43 & -0.42 & 3.42 & 0.02 \\
\hline $66 \ldots * \ldots$ & 0.51 & 0.76 & -0.25 & -1.41 & -2.02 & 0.02 \\
\hline$\left.89 \ldots\right|^{*} \ldots$ & 0.69 & 0.42 & 0.27 & -2.48 & 2.15 & 0.02 \\
\hline $124 \ldots * \ldots$ & 0.37 & 0.86 & -0.49 & -1.12 & -3.90 & 0.01 \\
\hline $125 \ldots * . \mid \ldots$ & 0.74 & 1.15 & -0.40 & -0.23 & -3.22 & 0.01 \\
\hline $126 \ldots * \mid \ldots$ & 0.91 & 1.25 & -0.34 & 0.08 & -2.73 & 0.01 \\
\hline $127 \ldots * \mid \ldots$ & 1.06 & 1.38 & -0.31 & 0.47 & -2.50 & 0.01 \\
\hline $128 \ldots * \mid \ldots$ & 1.20 & 1.48 & -0.28 & 0.79 & -2.25 & 0.01 \\
\hline $129 \ldots * \ldots$ & 1.28 & 1.54 & -0.26 & 0.97 & -2.07 & 0.01 \\
\hline Minimum ..*. $\mid \ldots$ & 0.37 & 0.30 & -0.49 & -2.83 & -3.90 & 0.01 \\
\hline Maximum ...|. .*.. & 1.51 & 1.54 & 0.43 & 0.97 & 3.42 & 0.03 \\
\hline Mean ....|* ... & 0.89 & 1.02 & -0.14 & -0.62 & -1.08 & 0.02 \\
\hline Median ...** . . & 0.83 & 1.12 & -0.27 & -0.33 & -2.16 & 0.01 \\
\hline
\end{tabular}

Tab. 6 shows significant deviations of model values compared to actual measured values. As regards minimum and maximum, explanation of the occurrence is relatively easy. We can notice that due to the nature of the test the initial and final measurement are in the zone that is most difficult to measure; the biggest error is in the initial deformation estimation and in the phase of plastic deformation or in the area of material breakdown.

The measurements were performed by a simple manual stress method and the problem of recording the initial deformation and deformation in the zone of plastic deformation and breakdown of the material is extremely difficult and subject to the subjective impression on the spot at the time of measurement.

\section{CONCLUSION}

The model is significant and shows with very high precision the behavior of the material when it comes to the stresses in real terms and the actual material that can be obtained as a raw material on a certain geographical micro location.

The accuracy of the applied multiple logarithmic model is $87.21 \%$. Therefore, we can conclude that the model is significant and applicable and has a very high accuracy of the deformation estimation in relation to the applied stress.

The research will continue in the direction of examining other properties such as the elasticity module etc. from which information would be obtained that would be useful for certain computer modelling when creating new products in a wide range of human activities including civil engineering and construction industry.

The results obtained by applying a multiple logarithmic model can be applied in defining and solving certain problems that require a response to the question of how deformation is and is allowed if there is a certain stress effect.

\section{REFERENCES}

[1] European Tyre \& Rubber Manufacturers' Association. (2015). End of life tyre report, http:/www.etrma.org/uploads/ Modules/Documentsmanager/elt-report-v9a---final.pdf

[2] Marsili, L., Coppola, D., Bianchi, N., Maltese, S., Bianchi, M., \& Fossi, M. C. (2014). Release of Polycyclic Aromatic Hydrocarbons and Heavy Metals from Rubber Crump in Synthetic Turf Fields: Preliminary Assessment for Athletes. Journal of Environmental and Analytical Toxicology, 5(2), 1000265. https://doi.org/10.4172/2161-0525.1000265

[3] Swedish Chemicals Inspecorate (2006). Synthetic turf from a chemical perspective - a status report 3/06 KEMIKemkalieinspektionen. Sundbyberg, Order. No. 510834 July 2006. e-mail:kemi@cm.se

[4] World Health Organization International Agency for Research on Cancer - IARC (2010). Monographs on the Evaluation of Carcinogenic Risks to Humans 1983. VOLUME 92 Some Nonheterocyclic Polycyclic Aromatic Hydrocarbons and Some Related Exposures, Lyon, France, 868.

[5] Simon, R. (2010). Review of the Impacts of Crumb Rubber in Artificial Turf Applications. UC Berkeley: Laboratory for Manufacturing and Sustainability. Retrieved from https://escholarship.org/uc/item/9zp430wp

[6] Birkholz, D. A., Belton, K. L., \& Guidotti, T. L. (2012). Toxicological Evaluation for the Hazard Assessment of Tire Crumb for Use in Public Playgrounds. Journal of the Air \& Waste Management Association, 53(7), 903-907. https://doi.org/10.1080/10473289.2003.10466221

[7] Watterson, A. (2017). Artificial Turf: Contested Terrains for Precautionary Public Health with Particular Reference to Europe? International Journal of Environmental Research and Public Health. https://doi.org/10.3390/ijerph14091050

[8] http://gumiimpex.hr

[9] HRN EN ISO 527-4:2008

[10] Nešić, N. (2014). Otkrivanje posledice prisustva heteroskedastičnosti. Univerzitet u Novom Sadu, Prirodnomatematički fakultet, Departman za matematiku i informatiku. Master rad, 90. (in Serbian)

Authors' contacts:

Anđelko CRNOJA, PhD student

Odessa State Academy of Civil Engineering and Architecture,

Didrihsona 4, 65029 Odessa, Ukraine

Tel: 00385992755466

E-mail: acrnoja@hotmail.com

Željko KOS, PhD

Corresponding author

University North,

31b, Jurja Krizanica, 42000 Varazdin, Croatia

Tel: 0038598757989

E-mail: zkos@unin.hr

Oleg POPOV, PhD, Assistant Professor

Department of Technology of Building Production,

Odessa State Academy of Civil Engineering and Architecture,

Didrihsona 4, 65029 Odessa, Ukraine

Tel: 00380503339753

E-mail: oleg.a.popov@gmail.com 